\title{
High-Resolution Vertical Profiles of X-Band Polarimetric Radar Observables during Snowfall in the Swiss Alps
}

\author{
MARC SCHNEEBELI \\ Environmental Remote Sensing Laboratory (LTE), School of Architecture, Environmental and Civil Engineering (ENAC), \\ École Polytechnique Fédérale de Lausanne, Lausanne, Switzerland

\section{NiCHOLAS DAWES} \\ Swiss Federal Institute for Forest Snow and Landscape Research (WSL)-Institute for Snow \\ and Avalanche Research (SLF), Davos, Switzerland \\ MiCHAEL LEHNING \\ Swiss Federal Institute for Forest Snow and Landscape Research (WSL)-Institute for Snow and Avalanche \\ Research (SLF), Davos, and School of Architecture, Environmental and Civil Engineering (ENAC), \\ Laboratory of Cryospheric Sciences, Lausanne, Switzerland \\ ALEXIS BERNE \\ Environmental Remote Sensing Laboratory (LTE), School of Architecture, Environmental and Civil Engineering (ENAC), \\ École Polytechnique Fédérale de Lausanne, Lausanne, Switzerland
}

(Manuscript received 5 January 2012, in final form 6 August 2012)

\begin{abstract}
An X-band polarimetric radar was deployed in the eastern Swiss Alps at an altitude of 2133 m. Radar measurements were complemented with several weather stations deployed in an altitude range from 1500 to $3100 \mathrm{~m}$ as well as with a fixed GPS ground station that was used to infer integrated water vapor estimates. Around 8000 vertical profiles of polarimetric radar observables above the melting layer collected during two months are analyzed. First, the behavior of the mean profiles of reflectivity at horizontal polarization $Z_{h}$, differential reflectivity $Z_{\mathrm{dr}}$, copolar cross correlation $\rho_{\mathrm{hv}}$, and specific differential phase shift $K_{\mathrm{dp}}$ are interpreted from a microphysical point of view. It is shown that the whole evolution of snowflakes, from pristine crystals at temperatures around $-30^{\circ} \mathrm{C}$ to dendritic crystals around $-15^{\circ} \mathrm{C}$, to large aggregates around $0^{\circ} \mathrm{C}$, is well captured by the polarimetric radar variables. In a second step, the profiles are analyzed as functions of high and low water vapor and snow accumulation conditions. It is found that the vertical profiles of polarimetric radar variables have distinct features in low versus high water vapor conditions. High water vapor conditions appear to favor the occurrence of crystal aggregates at high altitudes/low temperatures. It is shown with a hydrometeor identification scheme that graupel-like particles are found to be dominant right above the melting layer for snow events with high accumulation intensities. The present analyses show that measurements from X-band dual-polarization radar can be useful to characterize the dominant microphysical processes during precipitation in mountainous regions.
\end{abstract}

\section{Introduction}

The alpine region is vulnerable to natural disasters that are mostly caused by heavy precipitation events.

\footnotetext{
Corresponding author address: Marc Schneebeli, Environmental Remote Sensing Laboratory, École Polytechnique Fédérale de Lausanne, Station 2, Bât. GR, 1015 Lausanne, Switzerland.

E-mail: marc.schneebeli@epfl.ch
}

Because of their orography, the Alps themselves also have a huge impact on the flow patterns of air masses, directly influencing the precipitation distribution in all seasons. Accurate rainfall and especially snowfall observations are therefore needed to minimize disaster impact and to further the understanding of small-scale precipitation dynamics in mountainous regions. However, the complex alpine topography and the complex structure of the snow particles as well as the high spatial 
variability of snowfall induce difficulties for accurate quantitative estimation.

This article focuses on the vertical profiles of polarimetric radar variables in snowfall. The understanding of the behavior of these variables as functions of temperature, water vapor, and snow accumulation on the ground is necessary to improve our comprehension of solid precipitation formation and to improve its quantitative estimation. Despite the many dual-polarization weather radars distributed all over the world, knowledge of the behavior of the different polarimetric observables in snowfall is relatively poor. This is on one hand due to the large variability in size, shape, and density of the snow particles, which makes difficult the interpretation of the measured radar signals. On the other hand, the melting layer is another important reason why information is sparse. Most weather radars are located below the melting layer (in normal meteorological conditions) and therefore need to penetrate this layer to get information on the crystal and snow particles above. The melting layer is very absorbing and hence complicates quantitative analysis from such observations, especially at $\mathrm{C}$ and $\mathrm{X}$ band. Although there were attempts to model the influence of the melting layer on radar measurements (Bellon et al. 1997; Zawadzki et al. 2005; Matrosov 2008), the uncertainty associated with such corrections is still too large given the limited radar returns from snow or ice crystals. In the present study such difficulties are avoided by collecting measurements above the melting layer. Ice has a much lower dielectric constant than water and therefore it is common practice to leave the radar measurements uncorrected for attenuation, even at X-band frequencies (Matrosov 1992; Doviak and Zrnić 1993).

Disregarding the problems discussed so far, a few studies have been conducted about the behavior of the polarimetric variable profiles in snow. Almost 30 years ago, Hall et al. (1984) reported on the possibility of detecting different hydrometeor types with a dualpolarization radar. Vivekanandan et al. (1994) showed that a polarimetric radar is able to observe the transformation from ice crystals into aggregates. Ryzhkov and Zrnic (1998) analyzed S-band polarimetric radar measurements acquired during snow storms and found that the specific differential phase shift $K_{\mathrm{dp}}$ and the differential reflectivity $Z_{\mathrm{dr}}$ are not related to the behavior of the reflectivity at horizontal polarization $Z_{h}$ in dry snow. Very recently, Kennedy and Rutledge (2011) analyzed vertical profiles of polarimetric variables measured during a number of winter storms with the Colorado State University-University of Chicago-Illinois State Water Survey (CSU-CHILL) S-band radar. In these measurements, a distinct enhancement of $K_{\mathrm{dp}}$ at an altitude corresponding to $-15^{\circ} \mathrm{C}$ was found. Using a scattering model, this feature was interpreted as an effect of the dendrification process that is maximized at this temperature. In several studies (Matrosov et al. 1996, 2001; Reinking et al. 2002), the comparison of simulated and observed depolarization ratios showed that polarimetric measurements are well suited for the identification of ice hydrometeors types and shapes.

An interesting experimental study that enlightened some microphysical processes responsible for precipitation growth was presented in Evans et al. (2005). In the mentioned study, ground-based radar observations were combined with in situ particle identification instruments that were carried on a research aircraft. This combination of sensors allowed comprehensive analysis and interpretation of particle formation within a cyclonic storm.

Barthazy et al. (2001) presented results from the Mesoscale Alpine Programme (MAP) concerning the occurrence and detection of hydrometeor types employing a polarimetric S-band radar and ground-based in situ sensors and utilizing various hydrometeor identification (HID) schemes. The authors found good correlation between ground-based measurements and the HID scheme of the National Center for Atmospheric Research (NCAR; Vivekanandan et al. 1999) and therefore concluded that polarimetric radar measurements are well suited for studying the microphysics of precipitation. More generally, radar observations during MAP produced a wealth of results regarding the formation of alpine precipitation (e.g., Yuter and Houze 2003; Medina and Houze 2003) and can therefore be regarded as a milestone in the understanding of precipitation mechanisms in complex terrain.

Not only direct radar observations but also laboratory experiments helped to interpret the microphysical processes in winter clouds: the results from the classic study by Magono and Lee (1966) still provide a valid classification of the dominant particle growth regimes as a function of temperature and supersaturation over ice and the classification of different snow and ice crystal types found therein have been widely used until today. Recent studies (e.g., Bailey and Hallett 2009) confirm the findings of Magono and Lee (1966) and provide more details on the expected shapes of the snow crystals in different meteorological conditions.

The studies discussed above focus on S- or C-band radar systems and are generally based on limited datasets (a few hours or a few storms). The behavior of polarimetric radar variables at $\mathrm{X}$ band is therefore less documented and understood. To address these issues, an extensive field campaign has been conducted in the Swiss Alps. From September 2009 to July 2011, an $\mathrm{X}$-band polarimetric radar was deployed in Davos, 
Switzerland, at an altitude of $2133 \mathrm{~m}$. Furthermore, radar data were supplemented with ground-based measurements such as daily manual snow accumulation and snow density measurements, many weather stations, and integrated water vapor estimations derived from a fixed ground GPS station. From this large dataset a representative two-month period (end of February to end of April 2010) was extracted to apply a new approach for the characterization of microphysical processes involved in alpine snowfall by means of X-band polarimetric radar: Vertical profiles of radar polarimetric variables were first reprojected onto a uniform temperature grid and were later classified into high and low water vapor conditions as well as high and low snow accumulation conditions. As it will be shown, the chosen approach leads to insights into how microphysical processes that are driven by temperature and water vapor abundance are represented in the radar dataset and how these processes in the atmosphere are associated with high snowfall intensities on the ground. Although only marginally used in the present study, the instrumentation of the experimental site also consisted of three optical disdrometers [Ott Messtechnik, GmbH, laser-based particle size and velocity (Parsivel); Loffler-Mang and Joss 2000; Jaffrain et al. 2011] and one two-dimensional video disdrometer (2DVD; Kruger and Krajewski 2002). The data of these instruments will be used in upcoming studies on quantitative estimation of snowfall rates as well as for the validation of radar-based hydrometeor classification algorithms.

The paper is organized as follows: Section 2 describes the field campaign and the data used in this study. The vertical profiles of polarimetric variables are analyzed in section 3. A summary and conclusions are provided in section 4 .

\section{Field campaign in the Swiss Alps}

To document alpine precipitation (and especially snowfall), a field campaign was conducted in collaboration with the Swiss Federal Institute for Snow and Avalanche (SLF is the German acronym) in Davos. SLF manages (among other experimental sites) a long-term observatory for snow at $2640-\mathrm{m}$ altitude near the Weissfluhjoch $\left(46^{\circ} 50^{\prime} 0^{\prime \prime} \mathrm{N}, 9^{\circ} 48^{\prime} 23^{\prime \prime} \mathrm{E}\right)$. Among many quantities, daily manual snow height and density measurements as well as meteorological variables (temperature, humidity, and wind direction and speed) are of particular interest. In addition to this site, many sensors were deployed and a map with their locations is provided in Fig. 1. The following sections give more details about the instruments and datasets used in the present study.

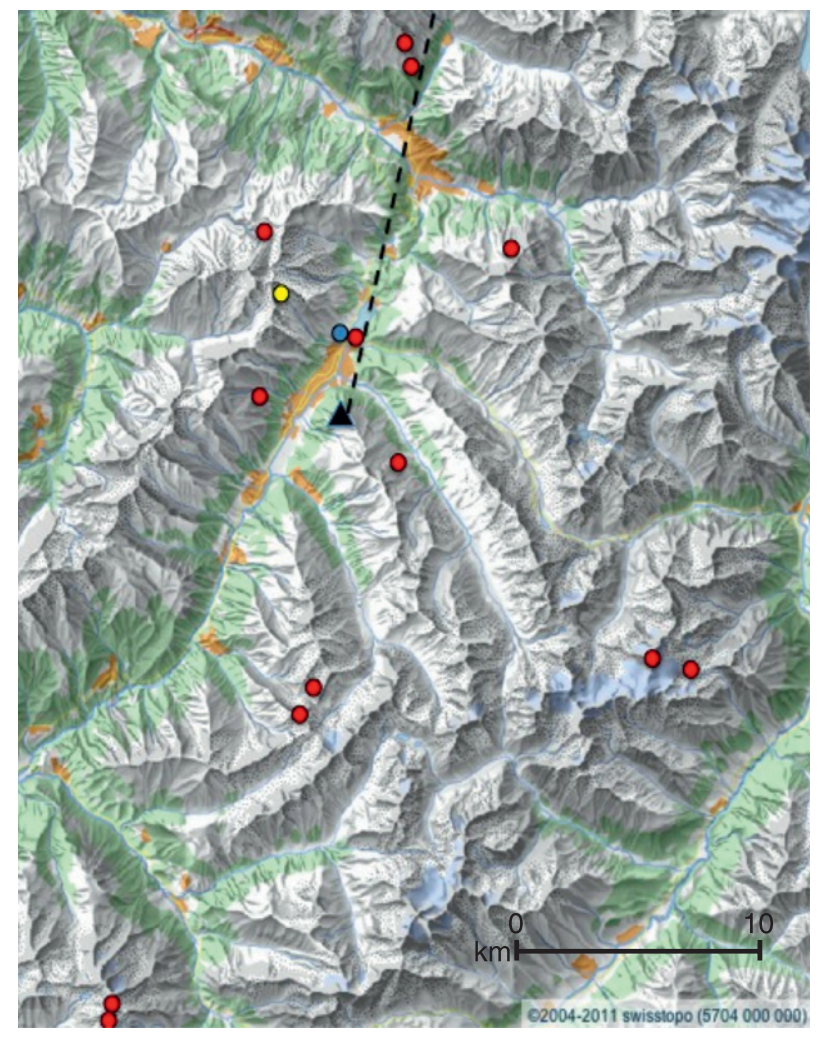

FIG. 1. Map indicating the location of the radar (black triangle), the direction of the RHI scan (dashed black line), and the different ground stations. Red circles: single weather station; yellow circle: weather station together with the $2 \mathrm{D}$ video disdrometer; blue circle: GPS receiver. Copyright 2011 swisstopo (JD100040), used by permission.

\section{a. Radar data}

A mobile 9.41-GHz Doppler dual-polarization radar (called MXPol), manufactured by ProSensing, was employed. Its main characteristics are summarized in Table 1. Shortly after the end of the two-month observation period, the radar calibration was checked with a trihedral corner reflector that was set up at four positions on the mountain ridge opposite the radar, at distances between 4 and $5 \mathrm{~km}$ from the radar (see Fig. 2b). The position of the reflector was determined by GPS and the radar scanned the reflector with high angular resolution. Finally, following the method described in Martner et al. (2003), the maximum reflectivity value was used for the determination of the radar calibration constant (see Fig. 2a). The radar calibration constant determined with this method was within $1.5 \mathrm{~dB}$ of that determined by the radar manufacturer. Although $1.5 \mathrm{dBZ}$ are not negligible, this value is within the accuracy range that can be reached with the corner reflector calibration method (Martner et al. 2003), hence the original constant was used for the calculation of the reflectivity values. 
TABLE 1. Specifications of MXPol.

Transmitter

Polarization

Pulses

Antenna

Antenna speed

Sampling

Scanning protocol

\author{
Magnetron delivering $7.5 \mathrm{~kW}$ per channel \\ Simultaneous horizontal and vertical transmission \\ Staggered pulse repetition interval (PRI) mode; PRIs of $950 \mu \mathrm{s}$ and $1200 \mu \mathrm{s}$; pulse length \\ of $0.25 \mu \mathrm{s}$ (37.5-m radial resolution) \\ $1.8-\mathrm{m}$ diameter; $1.4^{\circ} 3-\mathrm{dB}$ beamwidth. \\ $6^{\circ} \mathrm{s}^{-1}$ \\ 154 pulses per ray for $1^{\circ}$ angular resolution \\ 4 plane position indicator (PPI) scans $\left(0^{\circ}, 2^{\circ}, 5^{\circ}, 9^{\circ}\right.$ elevation), 1 RHI scan ( $76^{\circ}$ azimuth), \\ 3 PPI scans $\left(14^{\circ}, 20^{\circ}, 27^{\circ}\right.$ elevation $), 1$ RHI scan; whole scan within 5 min
}

During normal operation of the radar $Z_{\mathrm{dr}}$ is calibrated after every observation cycle by rotating the antenna while it points to zenith direction. The $Z_{\mathrm{dr}}$ average over a $360^{\circ}$ rotation is expected to be zero and any bias is removed in subsequent $Z_{\mathrm{dr}}$ measurements. Only measurements above the melting layer are considered and dry snow is not expected to significantly attenuate the radar signal (e.g., Doviak and Zrnić 1993).

Vertical profiles of $Z_{h}, Z_{\mathrm{dr}}, K_{\mathrm{dp}}$, and copolar cross correlation $\rho_{\mathrm{hv}}$ are extracted from the range-height-indicator (RHI) scan that was performed every $5 \mathrm{~min}$. The quantities $K_{\mathrm{dp}}\left({ }^{\circ} \mathrm{km}^{-1}\right)$ and $Z_{h}\left(\mathrm{~mm}^{6} \mathrm{~m}^{-3}\right)$ can be expressed as follows (e.g., Bringi and Chandrasekar 2001):

$$
K_{\mathrm{dp}}=\frac{180 \lambda}{\pi} \int_{D_{\text {min }}}^{D_{\max }} \Re\left[f_{\mathrm{hh}}(D)-f_{\mathrm{vv}}(D)\right] \bar{N}(D) d D
$$

and

$$
Z_{h, v}=\frac{4 \lambda^{4}}{\pi^{4}}\left|\frac{N_{r}^{2}+2}{N_{r}^{2}-1}\right| \int_{D_{\min }}^{D_{\max }}\left|s_{\mathrm{hh}, \mathrm{vv}}(D)\right|^{2} \bar{N}(D) d D,
$$

where $\lambda$ is the wavelength $(\mathrm{mm}), N_{r}$ is the refractive index of water (dimensionless), $f_{\mathrm{hh}, \mathrm{vv}}$ is the forward- and $s_{\mathrm{hh}, \mathrm{vv}}$ is the backward-scattering amplitude in meters at horizontal (hh) or vertical (vv) polarization. Here $\bar{N}(D)$ denotes the particle size distribution within the considered radar sampling volume and $D$ is the equivolumetric diameter of the particles (mm); $\Re$ denotes the real part of a complex number.

The following equation can be used for the determination of $\rho_{\mathrm{hv}}$ (e.g., Torlaschi and Gingras 2003):

$$
\rho_{\mathrm{hv}}=\left|\frac{S_{\mathrm{hv}}}{S_{\mathrm{hh}} S_{\mathrm{vv}}}\right|,
$$

where $S_{\mathrm{hh}}$ and $S_{\mathrm{vv}}$ denote the voltage covariance at horizontal and vertical polarization while $S_{\mathrm{hv}}$ denotes the cross covariance between the two polarization states.

From the definition of the differential reflectivity $Z_{\mathrm{dr}}=$ $10 \log _{10}\left(Z_{h} / Z_{v}\right)$ and expressing the particle size distribution as $\bar{N}(D)=N_{t} f(D)$, where $N_{t}$ is the total concentration of particles in a volume and $f(D)$ is a probability density function, it is seen that $N_{t}$ cancels out in the calculation of $Z_{\mathrm{dr}}$. Therefore, $Z_{\mathrm{dr}}$ is independent of the hydrometeor concentration. The $K_{\mathrm{dp}}$ was calculated from the total differential phase shift $\Psi_{\mathrm{dp}}$ by applying a newly developed Kalman filter algorithm (Schneebeli and Berne 2012).
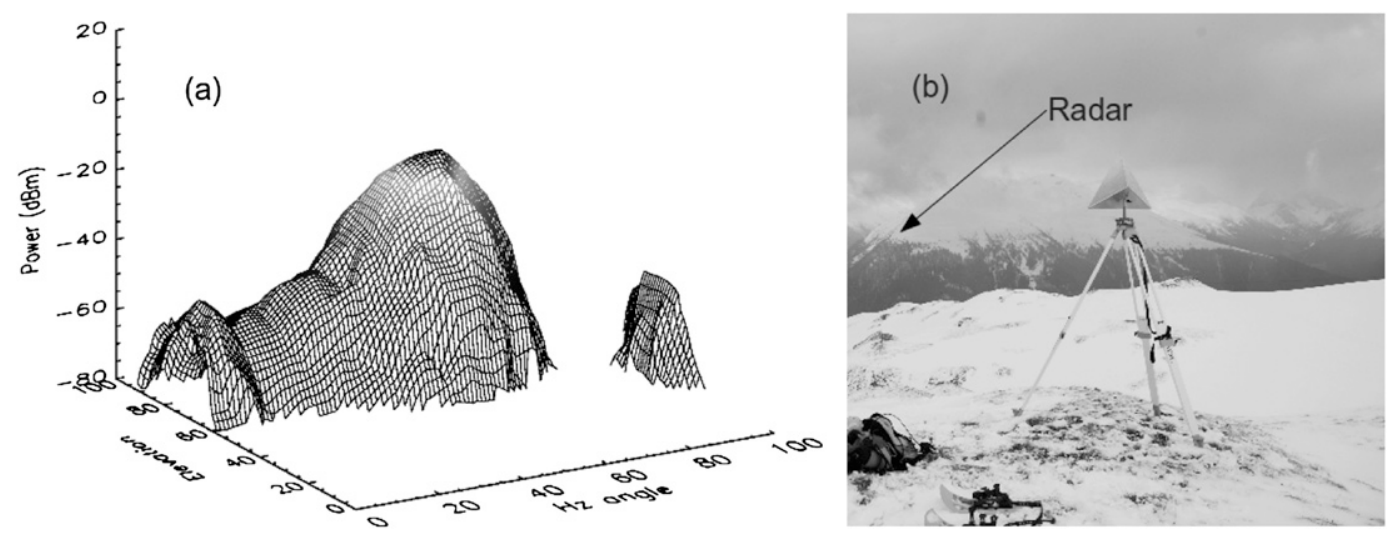

FIG. 2. (a) The reflected power $(\mathrm{dB} m)$ from the corner reflector as a function of the antenna's azimuth and elevation. Data were taken on 12 May 2010. (b) Picture of the corner reflector setup with the mountain range where the radar is located in the background. 

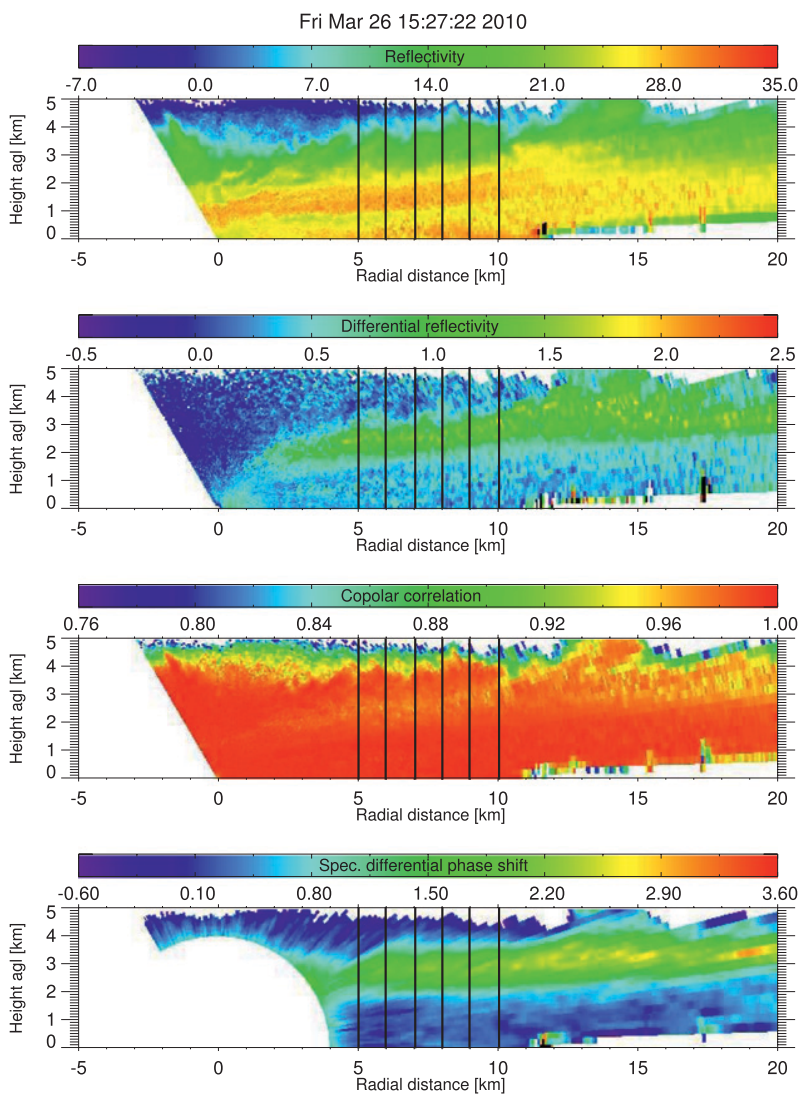

FIG. 3. Example of the polarimetric observables from one RHI scan performed on 26 Mar 2010. The black lines indicate the positions from where the vertical profiles are extracted in the further analysis.

RHI data were converted into a Cartesian coordinate system with $40-\mathrm{m}$ resolution by nearest-neighbor interpolation. From one RHI scan, five vertical profiles were extracted, each having a horizontal spacing of $1 \mathrm{~km}$ from the next one and the closest profile having a distance of $5 \mathrm{~km}$ from the radar to have a strong enough polarization signal at high elevation angles (which is further corrected for elevation angle effects). A distance of $1 \mathrm{~km}$ between the profiles was chosen so that the profiles are sufficiently independent from each other. An example of one RHI scan of the mentioned polarimetric variables is shown in Fig. 3.

Because of the harsh environmental conditions (cold temperatures, strong UV radiation), external flexible waveguides that connect the antenna to the pedestal quickly degraded and had to be replaced in January 2010. To avoid issues that are due to this change (in particular in calibration), we focus on the data collected between 25 February and 30 April 2010. During this period, the main types of snowfall (graupel, small to large aggregates, dendritic snow, and small crystal-like
TABLE 2. Thresholds applied for data filtering.

\begin{tabular}{ll}
\hline \hline Horizontal reflectivity $(\mathrm{dBZ})$ & $-10 \leq Z_{h} \leq 40$ \\
\hline Differential reflectivity $(\mathrm{dB})$ & $-1 \leq Z_{\mathrm{dr}} \leq 5$ \\
Copolar cross correlation $(-)$ & $0.75 \leq \rho_{\mathrm{hv}} \leq 1.0$ \\
Specific differential phase shift & $-2 \leq K_{\mathrm{dp}} \leq 7$ \\
\hline
\end{tabular}

snow) occurred during cold conditions in February to warmer conditions at the end of April, hence the dataset should be representative of alpine snowfall. About $133 \mathrm{~h}$ of precipitation were extracted from this 2-month period and will be used in this study.

\section{b. Selection, gridding, and postprocessing of radar data}

To remove polarimetric radar variables that are contaminated by interferences, clutter, brightband effects or high noise due to low signal-to-noise ratios (SNR), data were filtered by applying a number of thresholds. The values of these thresholds can be found in Table 2 . The thresholds were chosen regarding the limits for snow observations given in Dolan and Rutledge (2009). The margins in the cited study are inferred form theoretical scattering calculations that are based on the literature values of snow densities, size distributions and oblateness ratios for different snow types. Since the $\rho_{\mathrm{hv}}$ threshold given in Dolan and Rutledge (2009) does not take into account the effect of the decreasing SNR on $\rho_{\text {hv }}$ and therefore excludes too many valid measurements, an empirical threshold of $\rho_{\mathrm{hv}}=0.75$ was used. This value ensures that the SNR remains above approximately $3 \mathrm{~dB}$ (Melnikov and Zrnic 2007). In addition, only profiles that contained at least 25 data bins in the temperature range of $0^{\circ} \geq T \geq-32.5^{\circ} \mathrm{C}$ were considered in the analysis.

After this filtering process, about 8000 individual profiles remained and were included in the analysis. To be able to compare the individual profiles and to apply meaningful statistics to the ensemble, the data must be "normalized." Since temperature is the main driver for the evolution of snow and ice particles, we decided to regrid the original profiles (whose height coordinate origin is the radar altitude) onto a new height coordinate that uses the height of the $0^{\circ} \mathrm{C}$ level as the origin. This "normalization" allows better comparability between the profiles, and was also used by Kennedy and Rutledge (2011) for instance. Without the introduction of this new coordinate, the polarimetric profiles would be averaged over arbitrary temperature ranges, and hence the signals of microphysical processes that take place at specific temperatures would vanish from the mean profiles.

HID is a key tool for the understanding of microphysical processes in clouds and precipitation (e.g., 
Vivekanandan et al. 1999; Straka et al. 2000). We have implemented the HID scheme for X-band radars recently proposed by Dolan and Rutledge (2009). This fuzzy-logic scheme is based on overlapping one-dimensional membership functions of the observables $Z_{h}, Z_{\mathrm{dr}}, K_{\mathrm{dp}}$, and $\rho_{\mathrm{hv}}$. Hydrometeors are classified as the following 5 types: aggregated snow (AG; large particles with low densities and high axis ratios), snow crystals (CR; small particles with high densities and low axis ratios), high-density graupel (HDG; particles with high densities and high axis ratios), low-density graupel (LDG; as before, but with a slightly lower density), and vertical ice (VI; small ice particles that are vertically aligned). Please see the original article for more details on this classification as well as on the characteristics of the different snow types. In the present study, we will consider that the CR category corresponds to pristine crystals and that graupel-like categories (HDG and LDG) indicate particles formed by riming.

\section{c. Temperature data}

Measurements of the air temperature $T$ from 13 weather stations located at different altitudes $h$ between 1607 and $3162 \mathrm{~m}$ MSL within a maximum distance of $20 \mathrm{~km}$ from the radar (see Fig. 1), have been used to estimate the altitude of the $0^{\circ} \mathrm{C}$ level. A constant temperature gradient $\Gamma$ representative for the considered two-month period was determined by linear regression of all the available $T(h)$ data. With this method, a value of $\Gamma=-6.7^{\circ} \mathrm{C} \mathrm{km}^{-1}$ was obtained, with a standard deviation of $\operatorname{std}(\Gamma)=1.01^{\circ} \mathrm{C} \mathrm{km}^{-1}$. This gradient was fitted to the actual temperature data to determine the $0^{\circ} \mathrm{C}$ level as well as all the above height-temperature relations. Temperature data were registered every $10 \mathrm{~min}$ and afterward linearly interpolated on the 5-min time grid of the radar RHI scans. Only data with negative temperature gradient and with a $0^{\circ} \mathrm{C}$ level below the radar altitude were considered. Positive temperature gradients (i.e., temperature inversion conditions) were only occasionally encountered, hence only few data of this kind had to be removed from the dataset.

\section{d. Snow accumulation}

Snow height measurements were obtained from 6 weather stations that are additionally equipped with an ultrasound-based snow height sensor (Marty 2004). Snow accumulation intensities (SAI) were calculated by dividing the snow height by the time interval of the data acquisition. Because snow can melt, settle, or drift, SAI can also be negative. Since in this study only the impact from precipitation is of importance, negative SAI values were not considered and were set to zero. Of course it is also possible that wind drift accumulates snow under the snow height sensor and therefore leads to positive SAI

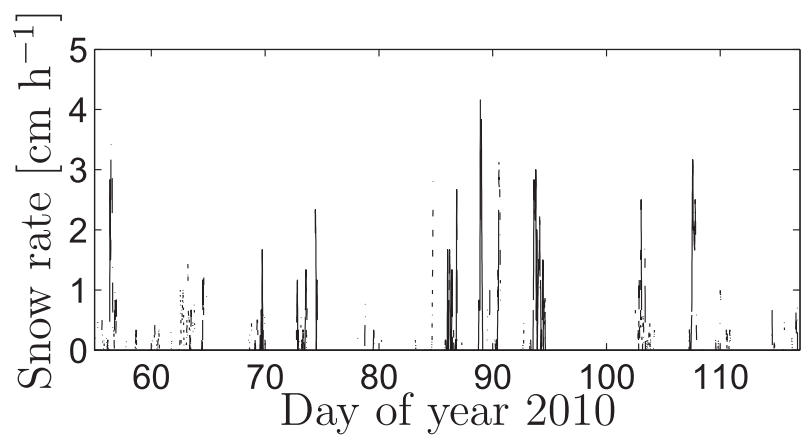

FIG. 4. Time series of the snow accumulation intensity between 25 Feb and 30 Apr 2010 in the region of Davos. Only data that coincide with radar data are plotted.

values in nonprecipitating conditions. In addition, the snow height sensor exhibits a temperature dependence; that is, the device itself has scatter in snow height and a diurnal pattern, thus differentiating will always produce some positive numbers. Since no absolute SAI values will be used in the further analysis but only relative quantiles that indicate periods of low and high snowfall intensities, SAI can still be regarded as a good qualitative indicator of the snowfall intensity in the considered area despite the mentioned uncertainties. As with the temperature data, SAI measurements were linearly interpolated on the RHI scan time grid. Periods of "high" and "low" SAI were determined by calculating the $33 \%$ and the $66 \%$ quantiles of the snow accumulation time series. SAI estimates that did not coincide in time with radar data considered for the analysis were removed beforehand from the time series. Periods that exhibited light snow accumulations when actually no snowfall occurred were therefore filtered out and did not contribute to the calculation of the quantiles that defined the low and high snowfall periods. The SAI time series whose values coincide with radar data is plotted in Fig. 4, resulting in the dashed-line aspect of the time series.

\section{e. Water vapor profiles}

The aforementioned 13 weather stations also delivered measurements of the relative humidity $(\mathrm{RH})$ at different height levels up to $3162 \mathrm{~m}$ MSL. Information about the humidity above this height was obtained with integrated water vapor (IWV) measurements that were calculated from the delay a GPS signal sustains on its way through the atmosphere. Instead of retrieving the exact position of the receiver, the integrated water vapor content of the atmosphere can be calculated when the position of the receiver is already known [for an overview of IWV measurements in Switzerland using GPS receivers, see Guerova et al. (2003)]. In our study the data from a GPS receiver located in the village of Davos 
at an altitude of $1550 \mathrm{~m}$ MSL were used. By removing the water vapor column that is contained between the ground and the highest (i.e., $3162 \mathrm{~m}$ ) weather station from the total GPS IWV column, the remaining IWV column above $3162 \mathrm{~m}$ can be calculated.

To do so, the water vapor density [WVD $\left.\left(\mathrm{g} \mathrm{m}^{-3}\right)\right]$ at height $h(\mathrm{~m})$ was calculated from relative humidity $[\mathrm{RH}$ $(-)]$ and $T(\mathrm{~K})$ values of the weather stations as

$$
\mathrm{WVD}(h)=\frac{\operatorname{mol}_{w} p(h) \mathrm{RH}(h) e_{s}}{k_{b} N_{A} T(h)\left[p(h)-\mathrm{RH}(h) e_{s}\right]},
$$

with the Boltzmann constant $k_{b}\left(\mathrm{~J} \mathrm{~K}^{-1}\right)$, the Avogadro number $N_{A}\left(\mathrm{~mol}^{-1}\right)$, the molar mass of water $\operatorname{mol}_{w}$ $\left(\mathrm{g} \mathrm{mol}^{-1}\right)$, and the saturation water vapor pressure $e_{s}$ $(\mathrm{Pa})$, which is a function of the temperature [an approximate fit can be found, e.g., in Rogers and Yau (1989)].

The atmospheric pressure values at the different weather station heights, $p\left(h_{i}\right)(\mathrm{Pa})$, that are necessary for this calculation, were determined with the hydrostatic equation given by (see, e.g., von Engeln et al. 2003)

$$
p\left(h_{i}\right)=p\left(h_{1}\right) / \exp \left[\Delta \Phi g_{a} /\left(R_{d} \overline{T^{v}}\right)\right],
$$

where $p\left(h_{1}\right)$ was measured at a station with an altitude of $h_{1}=1550 \mathrm{~m}$ MSL, $\Delta \Phi(\mathrm{m})$ denotes the difference in geopotential between height level $h_{1}$ and $h_{i}, g_{a}\left(\mathrm{~m} \mathrm{~s}^{-2}\right)$ is the gravitational acceleration, $R_{d}\left(\mathrm{~J} \mathrm{~mol}^{-1} \mathrm{~K}^{-1}\right)$ is the gas constant for dry air, and $\overline{T^{v}}(\mathrm{~K})$ is the mean virtual temperature between the layers $h_{1}$ and $h_{i}$. The required temperature and humidity information is obtained from the weather stations. WVD were then integrated over the height and the resulting water vapor column between 1550 and $3162 \mathrm{~m}$ MSL was subtracted from the total IWV:

$$
\mathrm{IWV}_{\text {trunc }}=\mathrm{IWV}_{\text {tot }}-\int_{1550 \mathrm{~m}}^{3162 \mathrm{~m}} \mathrm{WVD}(h) d h .
$$

From this integrated content, an approximate water vapor profile can be calculated by assuming an exponential decrease of the water vapor density with height (Schneebeli and Mätzler 2011):

$$
\operatorname{WVD}(h)=\mathrm{WVD}\left(h_{0}\right) e^{h / h_{s}},
$$

where $h_{s}(\mathrm{~m})$ denotes the water vapor scale height, which is calculated as

$$
h_{s}=\frac{\mathrm{IWV}_{\text {trunc }}}{\operatorname{WVD}\left(h_{3162}\right)} .
$$

To get one full profile over the whole troposphere, WVD profiles inferred from the weather stations and

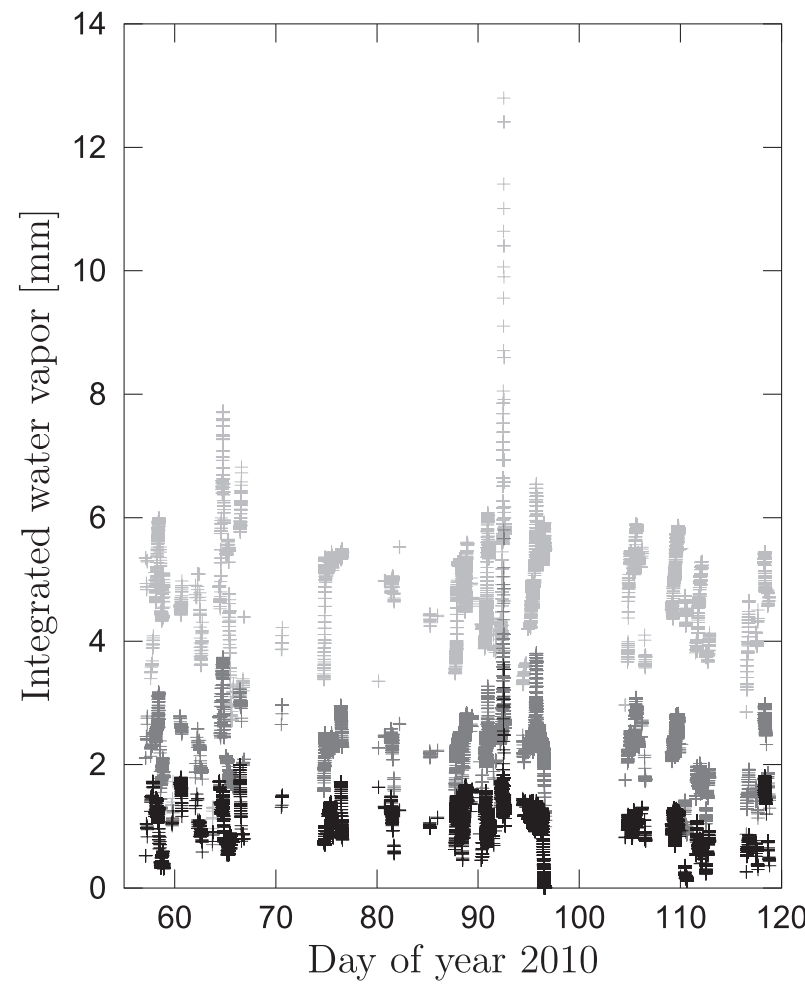

FIG. 5. Water vapor density integrated over three individual temperature ranges: $0^{\circ} \leq T<-10^{\circ} \mathrm{C}$ (light gray), $-10^{\circ} \leq T<-20^{\circ} \mathrm{C}$ (dark gray), and $-20^{\circ} \leq T<-32.5^{\circ} \mathrm{C}$ (black). In this plot as well as in the analysis, only water vapor data that coincide with radar data are used.

from the IWV measurement are combined to one profile and reprojected onto a height grid with the origin at the $0^{\circ} \mathrm{C}$ height. Certain profiles that were acquired in cold conditions where the $0^{\circ} \mathrm{C}$ height was below the lowermost weather station have missing values in the lowest levels. These levels were filled with the procedure that is detailed above with the same assumption of an exponentially increasing water vapor density with decreasing height. Finally, the water vapor was individually integrated over the three temperature ranges $0^{\circ} \geq T>-10^{\circ} \mathrm{C},-10^{\circ} \geq T>-20^{\circ} \mathrm{C}$, and $-20^{\circ} \geq T>-30^{\circ} \mathrm{C}$ to have an indication of the water vapor abundance within these tropospheric stories. These temperature intervals were chosen regarding the commonly used habit diagram of snow crystals (i.e., Mason 1971) that suggest that a dendrification region exists within the temperature range $-10^{\circ} \geq T>-20^{\circ} \mathrm{C}$, hence dividing the whole temperature range into three habit blocks (above dendrification, dendrification, below dendrification). The time series of the three integrated water vapor values for the different temperature regions is shown in Fig. 5. The data shown in this figure will be used in the upcoming analysis for the classification 

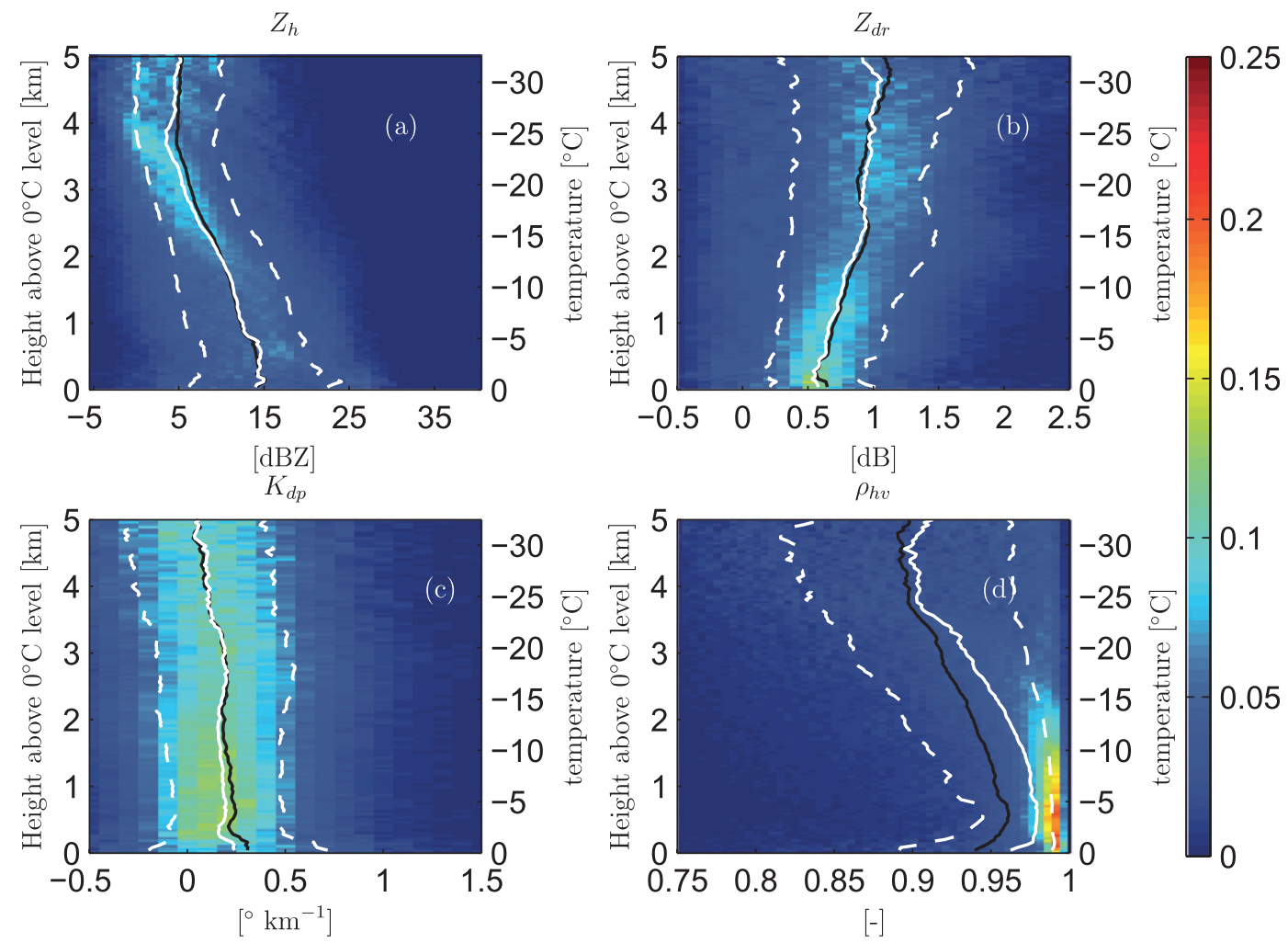

FIG. 6. Normalized distributions of polarimetric observables measured from 25 Feb to 30 Apr 2010. The black line indicates the mean of the distribution, the white dashed lines are the $20 \%$ and $80 \%$ quantiles, and the white solid line is the median: (a) $Z_{h}$, (b) $Z_{\mathrm{dr}}$, (c) $K_{\mathrm{dp}}$, and (d) $\rho_{\mathrm{hv}}$.

of the time series into periods of low and high water vapor conditions.

\section{Results and discussion}

\section{a. Overall distributions of vertical profiles of polarimetric radar variables}

In a first step, the polarimetric observables $Z_{\mathrm{dr}}$ and $K_{\mathrm{dp}}$ were corrected for their dependency on the viewing geometry. For $Z_{\mathrm{dr}}$, the correction formula given in Ryzhkov et al. (2005) is used and solved for $Z_{\mathrm{dr}}\left(\theta=0^{\circ}\right)$ ( $\theta$ is the elevation angle) while for $K_{\mathrm{dp}}$, the following formula is used that is inferred from simple geometrical considerations (L. Baldini 2012, personal communication):

$$
K_{\mathrm{dp}}\left(\theta=0^{\circ}\right)=\frac{2 K_{\mathrm{dp}}\left(\theta \neq 0^{\circ}\right)}{1+\cos (2 \theta)}
$$

Furthermore, all the available elevation-corrected profiles from the considered period were regridded as described in section $2 b$ and the distributions of the polarimetric observables as functions of the height above the $0^{\circ} \mathrm{C}$ level are plotted in Fig. 6 .
In addition, the polarimetric profiles served as an input for a hydrometeor identification scheme. The result of this classification for all the profiles is presented in Fig. 7. To compile this figure, the HID scheme was applied on every individual profile and the relative proportion of the individual hydrometeor classes was then calculated for every 40-m height level.

To understand the behavior of the different profiles, it is important to know the sensitivity of the polarimetric observables to particle oblateness, abundance, size, and density. According to Jameson (1983), $Z_{\mathrm{dr}}$ is the reflectivity weighted mean axis ratio (defined as the length of the vertical divided by the horizontal droplet axis) of the particle size distribution. Since large particles contribute more to the reflectivity than small particles, high $Z_{\mathrm{dr}}$ values are expected from particle size distributions including larger and more oblate particles. Smaller and more spherical particles that might also be present in the distribution do not contribute a lot to the $Z_{\mathrm{dr}}$ signal. Since the bulk density of snowflakes also has an influence on the reflectivity (the higher the particle density, the higher the reflectivity; e.g., Matrosov 1992), density in return directly influences $Z_{\mathrm{dr}}$, as illustrated in Kennedy and Rutledge (2011). In addition, the particle 


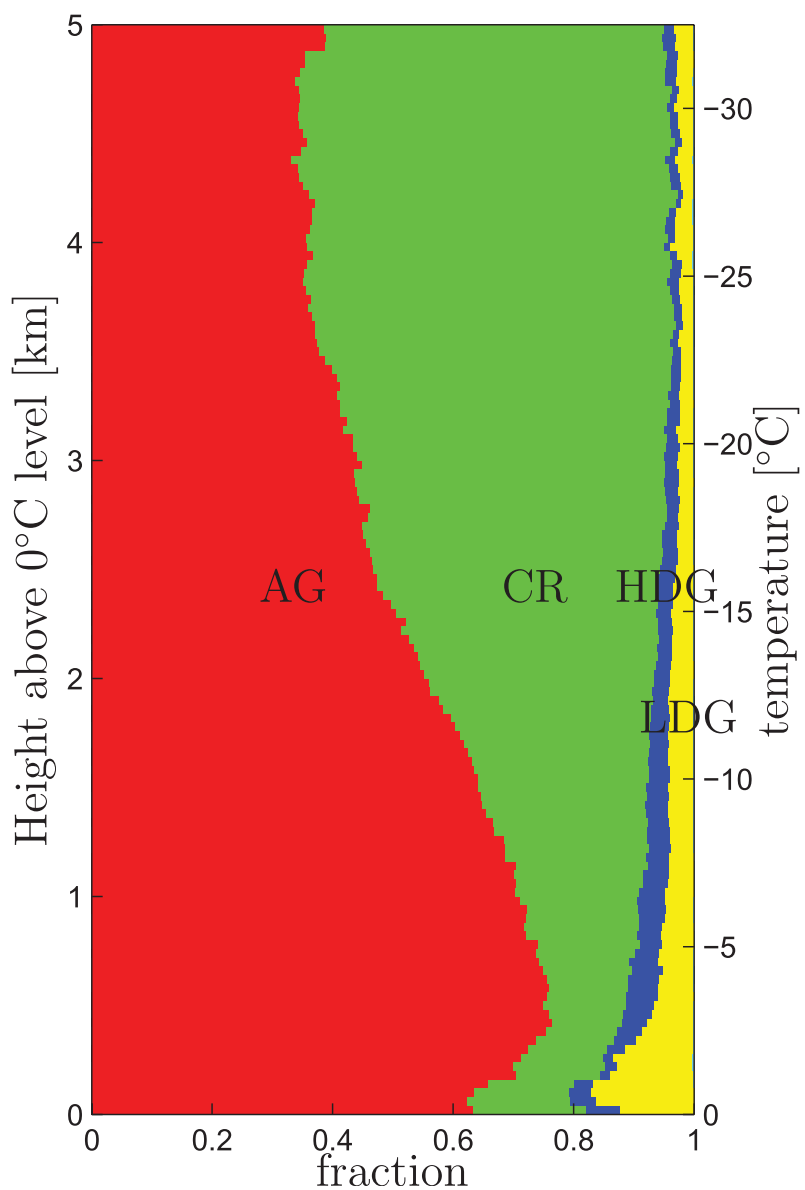

FIG. 7. Relative proportion of hydrometeors for all profiles according to the HID scheme by Dolan and Rutledge (2009). Hydrometeor types: AG (red), CR (green), HDG (blue), and LDG (yellow).

concentration has no influence on $Z_{\mathrm{dr}}$. In contrast, $K_{\mathrm{dp}}$ exhibits a mass weighted sensitivity to particle axis ratios. This means that a particle size distribution containing small and oblate particles and only few large and more spherical particles that do not account for the majority of the total mass of the particle distribution will have an elevated $K_{\mathrm{dp}}$ value. Contrary to $Z_{\mathrm{dr}}, K_{\mathrm{dp}}$ also depends on the concentration of particles. Since the particle density is directly related to the particle mass, $K_{\mathrm{dp}}$ is also dependent on variations in the particle bulk density. In Bringi and Chandrasekar (2001) the following approximate expression for $K_{\mathrm{dp}}$ for platelike ice particles can be found:

$$
K_{\mathrm{dp}}=10^{-3} \times\left(\frac{180^{\circ}}{\lambda}\right) C \rho_{p} \times \operatorname{IWC}(1-r) .
$$

Hereby, IWC $\left(\mathrm{g} \mathrm{m}^{3}\right)$ denotes the ice water content of the platelike particles, $\rho_{p}\left(\mathrm{~g} \mathrm{~cm}^{-3}\right)$ is the density of these particles, $\lambda(\mathrm{m})$ is the radar wavelength, and $C\left(\mathrm{~cm}^{6} \mathrm{~g}^{-2}\right)$ is a constant that depends on the radar wavelength. It must also be noted that $Z_{\mathrm{dr}}$ as well as $K_{\mathrm{dp}}$ depend on the orientation distribution of particles. Throughout the manuscript it is, however, assumed that the major axis of the particles is horizontally aligned. Finally, $\rho_{\mathrm{hv}}$ is a measure of the homogeneity of particle sizes and shapes within a radar sampling volume; therefore, low values indicate a mixture of different particles as abundant as each other. However, low $\rho_{\mathrm{hv}}$ values can also be found in regions with low reflectivity values since low signal-to-noise ratios also reduce the correlation between the horizontal and the vertical reflectivity. For the interpretation of the vertical profiles of polarimetric variables, we proceed from top to bottom, following the fall direction of the particles.

\section{1) Segment A: From $-32.5^{\circ} \mathrm{TO}-20^{\circ} \mathrm{C}$}

In this temperature range, the reflectivity $Z_{h}$ remains more or less constant in the range $-32.5^{\circ} \leq T<-25^{\circ} \mathrm{C}$, while it increases with increasing temperatures in the range $-20^{\circ} \geq T>-25^{\circ} \mathrm{C}$ (Fig. 6a). The mean of the differential reflectivity $Z_{\mathrm{dr}}$ roughly decreases with increasing temperature over the whole temperature range (Fig. 6b). In contrast, $K_{\mathrm{dp}}$ exhibits an almost constant gradient of about $\left(6 \times 10^{-3}\right)^{\circ} \mathrm{km}^{-1}{ }^{\circ} \mathrm{C}^{-1}$ over the temperature range with higher values to be found at higher temperatures (Fig. 6c). The increase of $Z_{h}$ and $K_{\mathrm{dp}}$ with increasing temperature is explained by the strong dependence of $Z_{h}$ and $K_{\mathrm{dp}}$ to the ice water content (Vivekanandan et al. 1994; Straka et al. 2000) and the generally increasing ice water content with decreasing altitude (e.g., Molthan et al. 2010; Hogan et al. 2006). The constant behavior of $Z_{h}$ and the high values of $Z_{\mathrm{dr}}$ at higher altitudes originate from the same process: In this region, pristine ice crystals such as plates and columns induce a high $Z_{\mathrm{dr}}$ signal (because of their low axis ratio and high density) and gradually transform into particles like assemblies of plates, capped columns, assemblies of columns, and assemblies of plates (for the nomenclature of the particles, see Magono and Lee 1966; Pruppacher and Klett 1997; Bailey and Hallett 2009) that appear more spherical to the radar, hence causing $Z_{\mathrm{dr}}$ to decrease with increasing temperature. In these temperature regions, hexagonal plates are the most abundant pristine crystals, since they grow right above the icesaturation equilibrium (Pruppacher and Klett 1997), while columnlike particles only grow in highly supersaturated conditions. According to the scattering calculations at X-band frequencies of Botta et al. (2008), hexagonal plates are highly reflective particles and hence these particles are able to compensate the $Z_{h}$ gradient caused by the change in ice water content that finally results 
in a constant reflectivity for temperatures colder than $-25^{\circ} \mathrm{C}$. In addition, the constancy of $Z_{h}$ can also be explained by the decrease in the bulk density of the particles with increasing temperatures (Molthan et al. 2010) and the fact that larger particles usually exhibit lower densities (e.g., Magono and Nakamura 1965). This decrease in the particle bulk density leads to a decrease in the reflectivity, which is compensated by the increase in the particle concentration. The fact that $K_{\mathrm{dp}}$ exhibits an almost constant increase despite this possible decrease in particle bulk density points to a rather strong increase in ice water content with increasing temperatures, which is able to overcompensate axisratio and bulk density effects on $K_{\mathrm{dp}}$.

The wide distribution of $Z_{\mathrm{dr}}$ within the considered temperature and altitude range indicates, however, that various saturation conditions take place that lead to a variety of different ice crystal sizes and shapes. The quantity $\rho_{\mathrm{hv}}$ finally parallels the increase of $K_{\mathrm{dp}}$ and $Z_{h}$ with increasing temperature and is therefore a consequence of the lower SNR at higher altitudes: lower reflectivities, that is, low signal values, result in a low SNR that induces a low correlation between the two polarizations (e.g., Torlaschi and Gingras 2003). The constant $Z_{h}$ region is, however, not represented in the $\rho_{\text {hv }}$ profile since pristine crystals can exhibit very low copolar correlation values (Dolan and Rutledge 2009), which leads to an ongoing reduction of the $\rho_{\mathrm{hv}}$ with increasing temperature.

From the hydrometeor identification given in Fig. 7, it is seen that the fraction of aggregates (which are more likely assemblages of crystals) is almost constant from the top of the profile down to about $-23^{\circ} \mathrm{C}$. Single crystallike particles dominate the distribution with an abundance of around $60 \%$. Toward higher temperatures, the abundance of aggregates increases slightly.

\section{2) SEGMEnT B: FROM $-20^{\circ} \mathrm{TO}-10^{\circ} \mathrm{C}$}

The most prominent feature within this temperature range is the $Z_{\mathrm{dr}}$ maximum around $-15^{\circ} \mathrm{C}$. This peak exhibits an average value of $0.965 \mathrm{~dB}$ and the $20 \%$ and $80 \%$ quantiles have values of 0.35 and $1.45 \mathrm{~dB}$, respectively. It can be explained by the dendrification process that starts at $T=-20^{\circ} \mathrm{C}$ and reaches a maximum at $T=-15^{\circ} \mathrm{C}$, as mentioned in Korolev et al. (2000) and Bailey and Hallett (2009), for example. During dendrification, the small pristine crystals or crystal assemblages grow by deposition of water vapor to form very oblate and relatively large particles. These highly reflective oblate particles explain the increase in $Z_{\mathrm{dr}}$. The large width of the $Z_{\mathrm{dr}}$ distribution around $-15^{\circ} \mathrm{C}$ is also noteworthy. It signifies that the particles can assume very different shapes (i.e., axis ratios) at this temperature and that

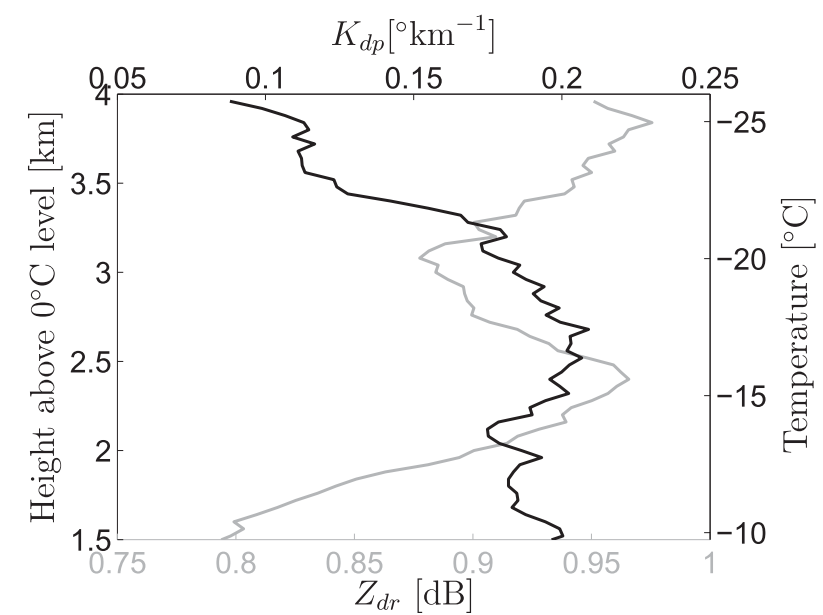

FIG. 8. Zoom on the mean $K_{\mathrm{dp}}$ (black) and $Z_{\mathrm{dr}}$ (gray) profiles from Fig. 6.

dendrification does not necessarily take place in all cases. For example, subsaturation conditions or a lack of particles suitable for initiating the dendrification process could lead to low $Z_{\mathrm{dr}}$ values in this temperature range.

Another maximum is found in the $K_{\mathrm{dp}}$ profile at approximately the same temperature as the $Z_{\mathrm{dr}}$ profile. Since several studies suggest that the dendrification process is also represented in the $K_{\mathrm{dp}}$ profile (Kennedy and Rutledge 2011; Bechini et al. 2011), it is assumed that the $K_{\mathrm{dp}}$ enhancement observed in our profile is also due to dendritic particles. As seen in the zoom of the $K_{\mathrm{dp}}$ and $Z_{\mathrm{dr}}$ profile (Fig. 8), the $K_{\mathrm{dp}}$ maximum is broader and less pronounced than the peak in the $Z_{\mathrm{dr}}$ profile. It seems that dendrification effects start to influence the $K_{\mathrm{dp}}$ profile at lower temperatures than the $Z_{\mathrm{dr}}$ profile. A possible explanation for this behavior is the fact that $K_{\mathrm{dp}}$ in contrast to $Z_{\mathrm{dr}}$ is affected by changes of the ice water content. Dendrites are formed in the temperature range where the water vapor excess (i.e., the difference between the actual vapor pressure of the ambient air and the vapor pressure at the surface of the ice particle) is greatest (e.g., Houze 1993), which implies that a lot of water vapor is available for the formation of ice crystals. In addition, dendrites have a very high surface-to-volume ratio, which gives the "increased ambient vapor more space on which to deposit" (Houze 1993). It is therefore expected that the ice water content is rapidly increasing, once the first dendrites were formed. According to Eq. (10), this rapid increase in the ice water content also leads to an increase in $K_{\mathrm{dp}}$, which in return shifts the $K_{\mathrm{dp}}$ dendrification maximum toward lower temperatures. It must, however, be kept in mind that $K_{\mathrm{dp}}$ is estimated from noisy $\Psi_{\mathrm{dp}}$ measurements, which can blur the peak in $K_{\mathrm{dp}}$. 
From several studies (e.g., Rauber 1987; Rogers and Yau 1989) it is known that if dendritic particles are present, significant aggregation is likely to occur. Aggregation is clearly visible in the $Z_{\mathrm{dr}}$ and $K_{\mathrm{dp}}$ profile where $T>-15^{\circ} \mathrm{C}$ : Suddenly, large and therefore highly reflective assemblages of dendrites with axis ratios close to 1 dominate the reflectivity (leading to a reduction of $Z_{\mathrm{dr}}$ ) and foster the major part of the particle total mass (leading to a reduction of $K_{\mathrm{dp}}$ ). The decrease in both $K_{\mathrm{dp}}$ and $Z_{\mathrm{dr}}$ is supported by a strong decrease in the particle bulk density that is caused by the aggregate growth of the dendritic particles. Aggregation and hence the reduction in $Z_{\mathrm{dr}}$ continues until the lower part of the considered temperature range. After a local minimum, $K_{\mathrm{dp}}$ continues to increase because of the increase in ice water content.

The dendrification process that takes place in the temperature range $-20^{\circ}<T<-10^{\circ} \mathrm{C}$ is not well represented in the hydrometeor classification (Fig. 7): the fraction of aggregates and crystals remains almost constant for the temperature range of $-20^{\circ}<$ $T<-15^{\circ} \mathrm{C}$. This is explained by the fact that dendritic growth of a snowflake originates from a stationary thin regular hexagonal plate (Mason 1993), that is, a pristine crystal that is classified into the "crystal" category of the employed HID scheme. The dendrite that developed out of the hexagonal plate remains in the crystal category, hence no change in the abundances of the crystal classes is observed. For temperatures higher than $-15^{\circ} \mathrm{C}$, the fraction of aggregates starts to increase steadily because of the aforementioned aggregation of dendritic crystals. Adding a "dendrite" hydrometeor class to the HID algorithm would make the dendrification process visible in the HID scheme. Such a class would be characterized with nonzero membership functions for high $K_{\mathrm{dp}}$ and $Z_{\mathrm{dr}}$ values as well as low $Z_{h}$ values to distinguish the polarimetric signature induced by dendrites from the one that is caused by graupel particles.

\section{3) SEgment C: FROM $-10^{\circ}$ TO $0^{\circ} \mathrm{C}$}

Within this range, the ice water content continues to increase with increasing temperature, which is paralleled in the general behavior of $K_{\mathrm{dp}}$ and $Z_{h}$. The process of aggregation is ongoing, hence the decrease of $Z_{\mathrm{dr}}$ with increasing temperature, which is amplified with the decrease in particle density with increasing temperature. An interesting behavior of the $K_{\mathrm{dp}}$ and $Z_{\mathrm{dr}}$ profiles is observed for $T>-5^{\circ} \mathrm{C}$ : a slight decrease of both variables is followed by another increase until the $0^{\circ} \mathrm{C}$ is reached. Within the same temperature range, the $\rho_{\mathrm{hv}}$ profile exhibits a pronounced drop and reaches a local minimum at $0^{\circ} \mathrm{C}$.
From the hydrometeor identification given in Fig. 7 it is seen that the amount of LDG, which corresponds to particles produced by riming processes, is steadily increasing with increasing temperature with an over proportional increase in the lowermost kilometer of the profile. Enhanced riming above the melting layer has also been reported in Houze and Medina (2005) with the explanation that a higher availability of supercooled liquid water is expected at higher temperatures. The increased abundance of graupel particles that is caused by this process was qualitatively confirmed with measurements performed by the $2 \mathrm{D}$ video disdrometer (Schneebeli et al. 2010). Riming, that is, the deposition of supercooled liquid water drops on ice crystals and/ or aggregates, is expected to lead to a reduction of $\rho_{\mathrm{hv}}$ because of the presence of different particle types (crystals, rimed crystals, graupel) in the same resolution volume. The uncertainty in the calculation of the temperature coordinates could, however, result in the inclusion of measurements collected within the melting layer. Such values could also explain the observed decrease in $\rho_{\mathrm{hv}}$.

In a zone at temperatures above $-5^{\circ} \mathrm{C}$ where secondary ice particles due to collision breakup can be produced (i.e., Hallet-Mossop secondary ice generation; Hallet and Mossop 1974), Moisseev et al. (2009) found a $Z_{\mathrm{dr}}$ profile that is similar to our measurements (i.e., a rapid change from decreasing to increasing $Z_{\mathrm{dr}}$ with increasing temperatures). This process could partly explain the observed $K_{\mathrm{dp}}$ and $Z_{\mathrm{dr}}$ profiles: While riming (being a prerequisite for the Hallett-Mossop process) first reduces $Z_{\mathrm{dr}}$ and $K_{\mathrm{dp}}$ because of an increase of the axis ratios of the particles, the breakup of these rimed crystals produces splinters that rapidly grow in conditions of elevated water vapor and finally result in elevated $K_{\mathrm{dp}}$ and $Z_{\mathrm{dr}}$ signals. This process is only active in the temperature range from $-3^{\circ}$ to $-7^{\circ} \mathrm{C}$ with the maximum efficiency being at $-5^{\circ} \mathrm{C}$ (e.g., Cantrell and Heymsfield 2005), which means that our observations are at the lowermost temperature of the occurrence of this process. This fact and also the limited number of observations within this temperature range suggest that this explanation may need to be substantiated by additional investigations. In addition, habit diagrams like the one given in Mason (1971) show that a variety of different crystal sizes and shapes can be produced within the temperature range under consideration, ranging from hollow prisms $\left(-8^{\circ}<T<-5^{\circ} \mathrm{C}\right)$ to long needles $\left(-5^{\circ}<\right.$ $\left.T<-3^{\circ} \mathrm{C}\right)$ to solid prisms, plates, and dendrites $\left(-3^{\circ}<\right.$ $\left.T<-0^{\circ} \mathrm{C}\right)$. All these particles exhibit different polarimetric properties and it is therefore not straightforward to fully unravel the microphysical processes based on our measurements. 


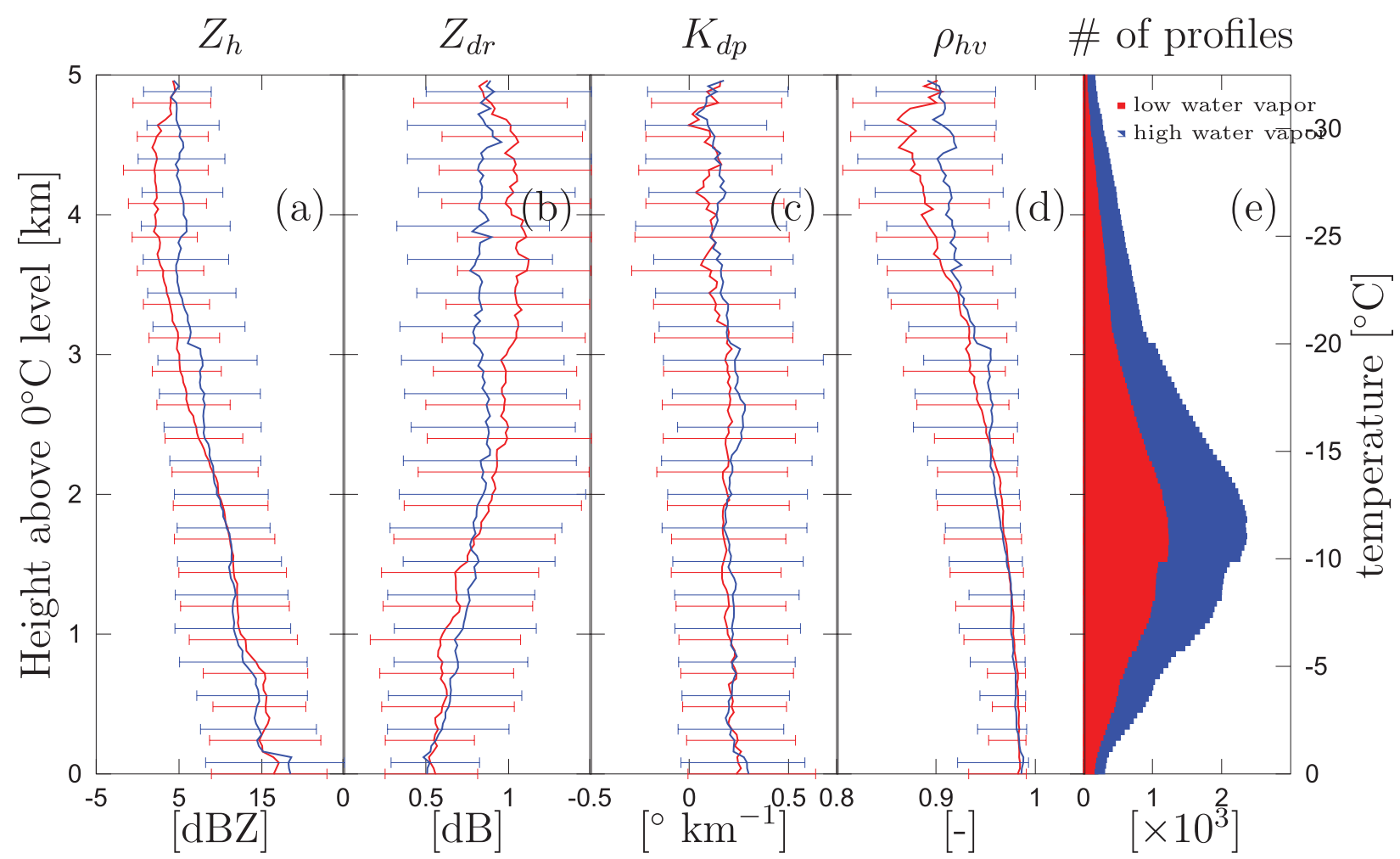

FIG. 9. (a)-(d) Mean vertical profiles of polarimetric observables above the melting layer classified for conditions of low and high water vapor conditions. The error bars indicate the $80 \%$ quantiles (for better readability, only every third error bar was plotted). (e) The total number of measurements for the individual classes.

\section{b. Vertical profiles as functions of the water vapor content}

\section{INTERPRETATION OF POLARIMETRIC VARIABLE PROFILES}

The water vapor measurements allow the polarimetric height profiles to be classified into profiles of low and high water vapor conditions. In section 2 , the process of obtaining water vapor columns, integrated over three temperature ranges was described. From these three individual time series (see Fig. 5), the $33 \%$ and $66 \%$ quantiles were calculated for the three temperature ranges. Profiles obtained in periods where the integrated water vapor was above the $66 \%$ quantile are grouped into the "high water vapor conditions" (HWVC) category, while integrated water vapor value below the $33 \%$ quantile served as a criterion for the "low water vapor conditions" (LWVC). The profiles were grouped individually for the three temperature ranges and finally averaged and compiled into one single profile. The result of this procedure is presented in Fig. 9. The corresponding profiles showing the distribution of hydrometeors for the two water vapor classes are given in Fig. 10.
While the overall profiles are relatively similar, the most dominant differences are found in the higher regions of the profiles, for temperatures $T<-15^{\circ} \mathrm{C}$. The $Z_{\mathrm{dr}}$ (Fig. 9b) profile at these temperatures especially exhibits a relatively clear difference between LWVC and HWVC. HWVC at high altitudes favors supersaturated conditions and in such an environment, the transition from pristine crystals into assemblages of crystals is simplified, as seen for example in Bailey and Hallett (2009). Therefore, less pristine (i.e., highly oriented and oblate) particles are present during these high vapor conditions, leading to reduced $Z_{\mathrm{dr}}$ values. This effect is also seen in the distribution of the hydrometeors given in Fig. 10: at high altitudes, the abundance of particles classified as aggregates is about $20 \%$ higher in HWVC conditions relative to LWVC conditions.

The profiles of $Z_{h}, \rho_{\mathrm{hv}}$, and also $K_{\mathrm{dp}}$ to a certain extent (Figs. 9a,c,d) exhibit higher values in HWVC within the temperature range $-15^{\circ}>T>-30^{\circ} \mathrm{C}$ than for LWVC, which is explained by the higher ice water content due to the higher abundance of water vapor. HWVC conditions lead to a higher supersaturation over ice, which directly leads to an increased diffusional 

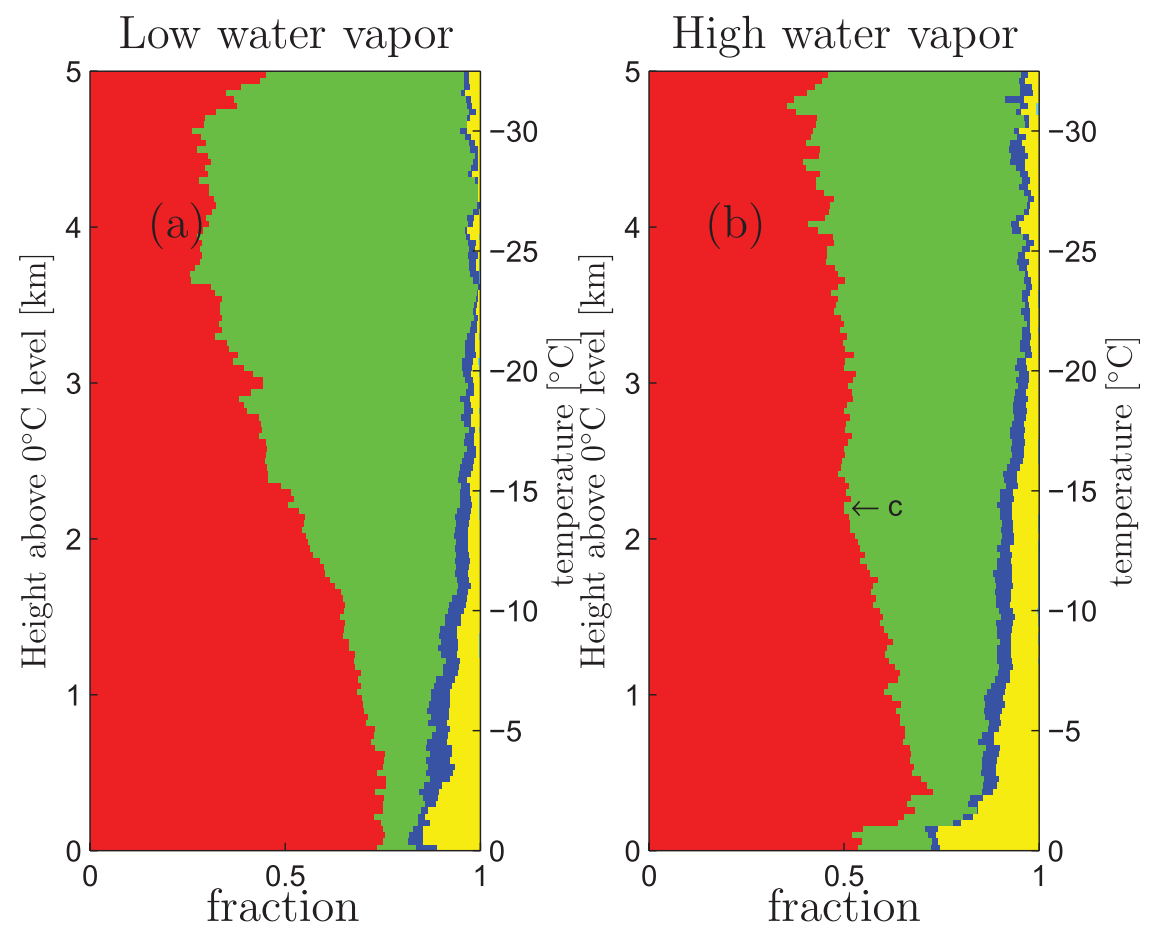

FIG. 10. The HID scheme applied on the profiles measured under (a) low and (b) high water vapor conditions. The color coding is similar to Fig. 7. The "c" in (b) indicates the dendrification signature (see text).

growth of ice crystals (e.g., Straka 2009) that contributes to a higher ice water content.

The dendrification process is visible in the $Z_{\mathrm{dr}}$ and $K_{\mathrm{dp}}$ profile in $\mathrm{HWVC}$ conditions. In the temperature range $-18^{\circ}<T<-12^{\circ} \mathrm{C}$, the $Z_{\mathrm{dr}}$ profile exhibits a clear maximum at $-15^{\circ} \mathrm{C}$ (Fig. 9b). Also $K_{\mathrm{dp}}$ (Fig. 9c) exhibits a maximum in this temperature range, although this is not as pronounced as the one of the $Z_{\mathrm{dr}}$ profile. It is not surprising that the dendrification maximum in the $Z_{\mathrm{dr}}$ and $K_{\mathrm{dp}}$ values is more prominent in HWVC. It seems that a lack of water vapor supply inhibits the formation of dendrites, which is in agreement with the Nakaya diagram (Pruppacher and Klett 1997, p. 42), which describes the habits of ice crystals as a function of temperature and supersaturation. From this diagram, it can be seen that in conditions of low supersaturation and at a temperature of $T=-15^{\circ} \mathrm{C}$, plates instead of dendrites are predominantly formed. In contrast to the overall distribution of hydrometeors (Fig. 7), the dendrification process is visible in the hydrometeor distribution in HWVC (Fig. 10b; feature is indicated with a "c"), where it can be seen that the abundance of crystals slightly increases within $-20^{\circ}<T<-15^{\circ} \mathrm{C}$. According to the explanation in the preceding section, crystals undergoing dendrification remain in the crystal category in the HID scheme, therefore it is believed that this process competes against aggregation, which already starts around $-18^{\circ} \mathrm{C}$ in LWVC.

Finally, differences between the two water vapor conditions are found for high temperatures $\left(T>-2^{\circ} \mathrm{C}\right)$ in the $Z_{h}$ profile (Figs. 9a). This difference is signature for the presence of graupel particles. Since saturation with respect to water is a prerequisite for riming to occur (because of the presence of liquid water droplets), it is not surprising that more graupel particles are formed in HWVC than in LWVC, as it is seen in the hydrometeor profiles. It is interesting to note that the increased abundance of graupel particles is produced at the expense of aggregates rather than crystals. Graupel can grow via collection growth, that is, a relatively large particle (snow crystal or aggregate) grows by collecting many smaller supercooled liquid water droplets. This process is enhanced when the diameters as well as the differences in the fall velocities of the involved snow particles and supercooled droplets are large (Pruppacher and Klett 1997, p. 617). Hence, large particles with fall velocities different from the fall velocity of the supercooled drops are able to collect more supercooled water. Aggregated snowflakes, having larger diameters and higher fall velocities than crystal-like snow (while the water droplets have very low fall velocities because of their small size), are therefore more likely to transform into graupel, 


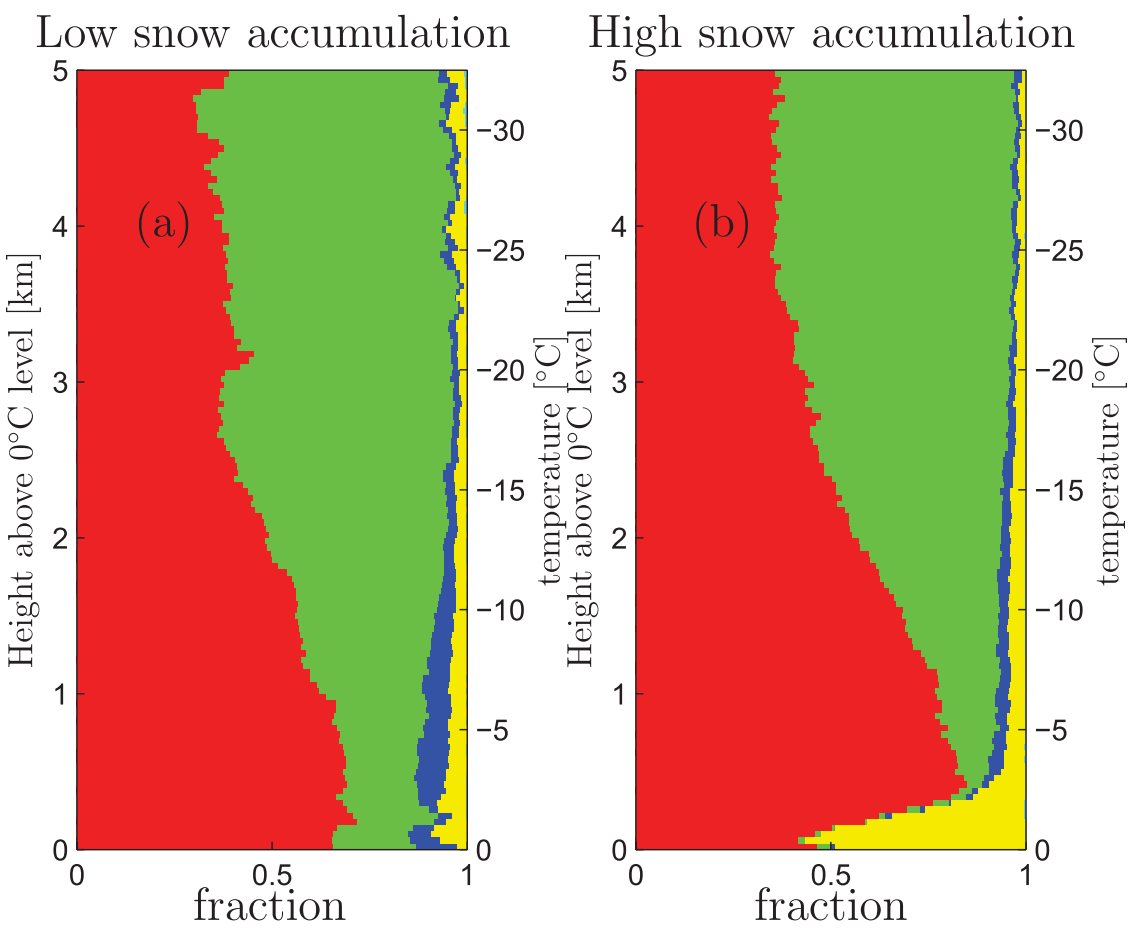

FIG. 11. As in Fig. 10, but for measurements made under conditions of (a) low and (b) high snow accumulation.

which is a reasonable explanation of the observed behavior.

It must also be kept in mind that this region is very close to the melting layer, where considerable changes in the polarimetric profiles are expected to happen. Hence, an error in the estimation of the temperature coordinate could lead to a contamination of the lowermost section of the polarimetric profiles. Since the $\rho_{\mathrm{hv}}$ profiles that are compiled for low and high water vapor conditions (Fig. 9) do not indicate any changes in this region, we expect the influence of this effect to be small. In contrast, the $\rho_{\text {hv }}$ profile that is calculated from the whole set of profiles (Fig. 6d) does exhibit a decrease in $\rho_{\mathrm{hv}}$ in this region, and it is therefore possible that the melting layer contaminates a couple of profiles that are used to plot the overall distribution of polarimetric variables, but these few measurements do not appear to be included in the selection of profiles that were used for the analysis concerning the different water vapor conditions.

\section{c. Vertical profiles as functions of snow accumulation}

The procedure performed for different water vapor classes is repeated for two different classes of the intensity of snow accumulation. Details on the classification were provided in section $2 \mathrm{~d}$. The polarimetric variable profiles binned into the two classes of low and high snow accumulation intensity are not shown since only marginal differences are visible between the classes. In contrast, the profiles of the hydrometeor classes are shown in Fig. 11. For temperatures $T<-20^{\circ} \mathrm{C}$ the distribution of hydrometeor types is relatively similar for the two snow accumulation conditions. For the temperature range of $-20^{\circ}<T<-3^{\circ} \mathrm{C}$, slightly more $(\approx 10 \%)$ particles classified as aggregates are observed in high compared to low snow accumulation conditions.

The most prominent difference between the two snow accumulation classes is found for $T>-3^{\circ} \mathrm{C}$, where a dramatic increase in the abundance of graupel-like snow is found in the class of high snow accumulation (Fig. 11b). According to observations made by Houze and Medina (2005) in the Alps during MAP and in mountains in Oregon, the occurrence of heavily rimed snow often leads to high precipitation intensity on the ground since particles gain weight (and therefore speed) during the riming process, which accelerates the fallout of the snowflakes. In addition, Harimaya and Nakai (1999) could also show the relation between riming and an increase in snowfall intensity for case studies in Japan. A high snowfall is also related to a high water vapor saturation, hence the similarities between the hydrometeor distribution in HWVC and in high snow accumulation conditions. The increase in graupel-like snow in the lowermost level of the profile is, however, much 
less pronounced when the profiles are classified with respect to integrated water vapor.

\section{Summary and conclusions}

About 8000 profiles of polarimetric X-band radar observables above the melting layer were collected from 25 February to 30 April 2010. The measured profiles, extracted from RHI scans along the Landwasser Valley, were reprojected on a height grid that starts at the $0^{\circ} \mathrm{C}$ level using temperature measurements from 13 neighboring weather stations at different altitudes. This data rearrangement paved the way for comparability and microphysical interpretation of the obtained profiles.

Looking at the vertical profiles of polarimetric radar variables averaged over the entire period analyzed, the dominance of pristine ice crystals in the upper part of the profiles (temperature below $-25^{\circ} \mathrm{C}$ ) is indicated by higher $Z_{\mathrm{dr}}$ values and the increasing particle concentration with increasing temperature is indicated by increasing $K_{\mathrm{dp}}$ values. For temperatures between $-20^{\circ}$ and $-15^{\circ} \mathrm{C}$, the dominant microphysical process is dendrification, as indicated by a local maximum in $Z_{\mathrm{dr}}$ at this temperature (see Figs. 6b, 8, 9b). For temperatures higher than $-15^{\circ} \mathrm{C}$, aggregation becomes dominant together with increasing concentration, as indicated by decreasing $Z_{\mathrm{dr}}$ values and increasing $Z_{h}$ values. The proposed evolution of snow crystals is confirmed by the outcome from the hydrometeor identification algorithm from Dolan and Rutledge (2009).

In a second step, the vertical profiles were separated into classes of low and high water vapor conditions (from profiles inferred from weather stations located at different heights and a GPS station) and snow accumulation rates (from ground-based weather stations). The availability of water vapor plays a crucial role in the microphysical evolution of snow crystals from cloud top to ground level. Cases of high water vapor favor the building of crystal assemblages at temperatures $T<-20^{\circ} \mathrm{C}$ and aggregation for $T>-5^{\circ} \mathrm{C}$. Although the dendrification of crystals via the Bergeron-Findeisen process is expected to depend on the availability of water vapor, no clear difference between high and low water vapor conditions could be observed in our data regarding this process. Since the employed water vapor profiles are prone to a variety of errors (time interpolation, height interpolation, spatial representativeness, GPS measurement uncertainty, pressure profile uncertainty, temperature profile uncertainty), it is assumed that the accuracy of the water vapor classification is not sufficient for unveiling such delicate processes. Additional uncertainties that stem from the radar measurement itself, like calibration errors, measurement noise as well as the uncertainties associated with the determination of $K_{\mathrm{dp}}$ further reduce the visibility of such microphysical processes in the data.

The main difference in the vertical profiles when analyzing the influence of low or high snow accumulation rates is the lower levels (temperature above $-5^{\circ} \mathrm{C}$ ), where the hydrometeor identification algorithm indicates a much larger proportion of graupel-like particles (formed by riming) in the case of high snow accumulation rate at the ground level, which is consistent with previous work.

Analysis of the variability of the vertical profiles of polarimetric radar variables collected at $\mathrm{X}$ band in alpine snowfall show that ( $\mathrm{X}$ band) polarimetric radars can provide useful insights into the microphysics of snowfall. The derived information remains rather qualitative because of the lack of in situ observations for the complete validation of the described behaviors. The study is, however, valuable since it shows that snow microphysical processes can be made visible with X-band polarimetric radars. Additional investigations involving electrodynamic modeling of polarimetric variables, modeling of snow microphysical behavior in different meteorological conditions as well as in situ observations should be conducted to further confirm the proposed hypotheses on the evolution of ice crystals during snowfall in mountainous regions.

Acknowledgments. The help of Marc Ruesch, Dani Lussi, and many others at the WSL-Institute for Snow and Avalanche Research SLF and Vali Meier and his team at the Davos-Klosters ski resort is greatly acknowledged as well as the financial support from the Swiss National Science Foundation (Grant 200021-125064) and the Swiss Center of Competence in Environmental Sciences (CCES). Integrated water vapor data were kindly provided by the Institute of Applied Physics, University of Bern, Switzerland, through the STARTWAVE database (www.iapmw.unibe.ch/STARTWAVE). Thanks go also to Xavier Muth for the positioning of the radar and for the radar calibration measurements and Samuel Jolivet for assistance in the maintenance of the radar.

\section{REFERENCES}

Bailey, M. P., and J. Hallett, 2009: A comprehensive habit diagram for atmospheric ice crystals: Conformation from the laboratory, AIRS II, and other field studies. J. Atmos. Sci., 66, 2888 2899.

Barthazy, E., S. Göke, J. Vivekanandan, and S. M. Ellis, 2001: Detection of snow and ice crystals using polarization radar measurements: Comparison between ground-based in situ and S-Pol observations. Atmos. Res., 59-60, 137-162.

Bechini, R., L. Baldini, V. Chandrasekar, R. Cremonini, and E. Gorgucci, 2011: Observations of KDP in the ice region of 
precipitating clouds at $\mathrm{X}$ - and C-band radar frequencies. Preprints, 35th Conf. on Radar Meteorology, Pittsburgh, PA, Amer. Meteor. Soc., 7A.4. [Available online at https://ams. confex.com/ams/35Radar/webprogram/Paper191528.html.]

Bellon, A., I. Zawadzki, and F. Fabry, 1997: Measurements of melting layer attenuation at X-band frequencies. Radio Sci., 32, 943-955.

Botta, G., D. Scaranari, M. Montopoli, and F. S. Marzano, 2008: Backscattering modeling for polarimetric radar observation of ice crystals and aggregates from C- to Ka-band. Preprints, Fifth European Conf. on Radar Meteorology and Hydrology, Helsinki, Finland, Finnish Meteorological Institute, 5 pp. [Available online at http://erad2008.fmi.fi/proceedings/extended/ erad2008-0221-extended.pdf.]

Bringi, V. N., and V. Chandrasekar, 2001: Polarimetric Doppler Weather Radar. Cambridge University Press, 662 pp.

Cantrell, W., and A. Heymsfield, 2005: Production of ice in tropospheric clouds. Bull. Amer. Meteor. Soc., 86, 795-807.

Dolan, B., and S. A. Rutledge, 2009: A theory-based hydrometeor identification algorithm for X-band polarimetric radars. J. Atmos. Oceanic Technol., 26, 2071-2088.

Doviak, R., and D. Zrnić, 1993: Doppler Radar and Weather Observations. 2nd ed. Academic Press, 562 pp.

Evans, A. G., J. D. Locatelli, M. T. Stoelinga, and P. V. Hobbs, 2005: The IMPROVE-1 storm of 1-2 February 2001. Part II: Cloud structures and the growth of precipitation. J. Atmos. Sci., 62, 3456-3473.

Guerova, G., E. Brockmann, J. Quiby, F. Schubiger, and C. Mätzler, 2003: Validation of NWP mesoscale models with Swiss GPS network AGNES. J. Appl. Meteor., 42, 141-150.

Hall, M. P. M., J. W. F. Goddard, and S. M. Cherry, 1984: Identification of hydrometeors and other targets by dual-polarization radar. Radio Sci., 19, 132-140.

Hallet, J., and S. C. Mossop, 1974: Production of secondary ice particles during the riming process. Nature, 249, 26-28.

Harimaya, T., and Y. Nakai, 1999: Riming growth process contributing to the formation of snowfall in orographic areas of Japan facing the Japan Sea. J. Meteor. Soc. Japan, 77, 101-115.

Hogan, R. J., M. P. Mittermaier, and A. J. Illingworth, 2006: The retrieval of ice water content from radar reflectivity factor and temperature and its use in evaluating a mesoscale model. J. Appl. Meteor. Climatol., 45, 301-317.

Houze, R. A., Jr., 1993: Cloud Dynamics. Academic Press, 573 pp.

— , and S. Medina, 2005: Turbulence as a mechanism for orographic precipitation enhancement. J. Atmos. Sci., 62, 3599-3623.

Jaffrain, J., A. Studzinski, and A. Berne, 2011: A network of disdrometers to quantify the small-scale variability of the raindrop size distribution. Water Resour. Res., 47, W00H06, doi:10.1029/2010WR009872.

Jameson, A. R., 1983: Microphysical interpretation of multiparameter radar measurements in rain. Part II: Estimation of raindrop distribution parameters by combined dual-wavelength and polarization measurements. J. Atmos. Sci., 40, 1803-1813.

Kennedy, P. C., and S. A. Rutledge, 2011: S-band dual polarization radar observations of winter storms. J. Appl. Meteor. Climatol., 50, 844-858.

Korolev, A., G. A. Isaac, and J. Hallett, 2000: Ice particle habits in stratiform clouds. Quart. J. Roy. Meteor. Soc., 126, 2873-2902.

Kruger, A., and W. F. Krajewski, 2002: Two-dimensional video disdrometer: A description. J. Atmos. Oceanic Technol., 19, 602-617.

Loffler-Mang, M., and J. Joss, 2000: An optical disdrometer for measuring size and velocity of hydrometeors. J. Atmos. Oceanic Technol., 17, 130-139.
Magono, C., and T. Nakamura, 1965: Aerodynamic studies of falling snowflakes. J. Meteor. Soc. Japan, 43, 139-147.

- and C. W. Lee, 1966: Meteorological classification of natural snow crystals. J. Fac. Sci. Hokkaido Univ. Ser. 7, 2, 321-335.

Martner, B. E., K. A. Clark, and B. W. Bartram, 2003: Radar calibration using a trihedral corner reflector. Preprints, 31st Conf. on Radar Meteorology, Seattle, WA, Amer. Meteor. Soc., P3C.8. [Available online at https://ams.confex.com/ ams/32BC31R5C/webprogram/Paper63895.html.]

Marty, C., 2004: Snow monitoring in the Swiss Alps. Global Environmental and Social Monitoring: Proceedings of the 1st International Thematic Workshop Held in Vienna, Austria, 9-11 May 2004, C. Lee and T. Schaaf, Eds., UNESCO, 43-45.

Mason, B. J., 1971: The Physics of Clouds. 2nd ed. Clarendon Press, $671 \mathrm{pp}$.

_ 1993: Growth habits and growth rates of snow crystals. Proc. Roy. Soc. London, A441, 3-16.

Matrosov, S. Y., 1992: Radar reflectivity in snowfall. IEEE Trans. Geosci. Remote Sens., 30, 454-461.

- 2008: Assessment of radar signal attenuation caused by the melting hydrometeor layer. IEEE Trans. Geosci. Remote Sens., 46, 1039-1047, doi:10.1109/TGRS.2008.915757.

, R. F. Reinking, R. A. Kropfli, and B. W. Bartram, 1996: Estimation of ice hydrometeor types and shapes from radar polarization measurements. J. Atmos. Oceanic Technol., 13, 85-96.

,,,--- B. E. Martner, and B. W. Bartram, 2001: On the use of radar depolarization ratios for estimating shapes of ice hydrometeors in winter clouds. J. Appl. Meteor., 40, 479-490.

Medina, S., and R. A. Houze Jr., 2003: Air motions and precipitation growth in alpine storms. Quart. J. Roy. Meteor. Soc., 129, 345-371, doi:10.1256/qj.02.13.

Melnikov, V. M., and D. S. Zrnic, 2007: Autocorrelation and crosscorrelation estimators of polarimetric variables. J. Atmos. Oceanic Technol., 24, 1337-1350.

Moisseev, D., E. Saltikoff, and M. Leskinen, 2009: Using dualpolarization weather radar observations to improve quantitative precipitation estimation in snowfall. Proceedings of the 8th International Symposium on Tropospheric Profiling, A. Apituley, H. W. J. Russchenberg, and W. A. A. Monna, Eds., Royal Netherlands Meteorological Institute, S11-O04. [Available online at http://cerberus.rivm.nl/ISTP/data/1712984.pdf.]

Molthan, A. L., W. A. Petersen, S. W. Nesbitt, and D. Hudak, 2010: Evaluating the snow crystal size distribution and density assumptions within a single-moment microphysics scheme. Mon. Wea. Rev., 138, 4254-4267.

Pruppacher, H. R., and R. L. Klett, 1997: Microphysics of Clouds and Precipitation. 2nd ed. Atmospheric and Oceanographic Sciences Library, Vol. 18, Kluwer Academic Press, 954 pp.

Rauber, R. M., 1987: Characteristics of cloud ice and precipitation during wintertime storms over the mountains of northern Colorado. J. Climate Appl. Meteor., 26, 488-524.

Reinking, R. F., S. Y. Matrosov, R. A. Kropfli, and B. W. Bartram, 2002: Evaluation of a $45^{\circ}$ slant quasi-linear radar polarization state for distinguishing drizzle droplets, pristine ice crystals, and less regular ice particles. J. Atmos. Oceanic Technol., 19, 296-321.

Rogers, R. R., and M. K. Yau, 1989: Cloud Physics. 3rd ed. Pergamon, $293 \mathrm{pp}$

Ryzhkov, A. V., and D. S. Zrnic, 1998: Discrimination between rain and snow with a polarimetric radar. J. Appl. Meteor., 37, 12281240 . 
S. E. Giangrande, V. E. Melnikov, and T. J. Schuur, 2005: Calibration issues of dual-polarization radar measurements. J. Atmos. Oceanic Technol., 22, 1138-1155.

Schneebeli, M., and C. Mätzler, 2011: A radiative transfer model for an idealized and non-scattering atmosphere and its application for ground-based remote sensing. J. Quant. Spectrosc. Radiat. Transfer, 112, 883-892.

, and A. Berne, 2012: An extended Kalman filter framework for polarimetric X-band weather radar data processing. J. Atmos. Oceanic Technol., 29, 711-730.

, — - S. Jolivet, X. Muth, J. Jaffrain, N. Dawes, and M. Lehning, 2010: Measurements of alpine precipitation with an x-band polarimetric radar and additional sensors. Proc. Sixth European Conf. on Radar in Meteorology and Hydrology: Advances in Radar Technology, Sibiu, Romania, ERAD. [Available online at http://www.erad2010.org/pdf/POSTER/ Thursday/02_Xband/15_ERAD2010_extended.pdf.]

Straka, J. M., 2009: Cloud and Precipitation Microphysics: Principles and Parameterizations. Cambridge University Press, 392 pp.

, D. S. Zrnic, and A. V. Ryzhkov, 2000: Bulk hydrometeor classification and quantification using polarimetric radar data: Synthesis of relations. J. Appl. Meteor., 39, 1341-1372.
Torlaschi, E., and Y. Gingras, 2003: Standard deviation of the copolar correlation coefficient for simultaneous transmission and reception of vertical and horizontal polarized weather radar signals. J. Atmos. Oceanic Technol., 20, 760-766.

Vivekanandan, J., V. N. Bringi, M. Hagen, and P. Meischner, 1994: Polarimetric radar studies of atmospheric ice particles. IEEE Trans. Geosci. Remote Sens., 32, 1-10.

— D. S. Zrnic, S. M. Ellis, R. Oye, A. V. Ryzhkov, and J. Straka, 1999: Cloud microphysics retrieval using S-band dual-polarization radar measurements. Bull. Amer. Meteor. Soc., 80, 381-388.

von Engeln, A., G. Nedoluha, G. Kirchengast, and S. Bühler, 2003: One-dimensional variational (1-D Var) retrieval of temperature, water vapor, and a reference pressure from radio occultation measurements: A sensitivity analysis. J. Geophys. Res., 108, 4337, doi:10.1029/2002JD002908.

Yuter, S. E., and R. A. J. Houze, 2003: Microphysical modes of precipitation growth determined by S-band vertically pointing radar in orographic precipitation during MAP. Quart. J. Roy. Meteor. Soc., 129, 455-476.

Zawadzki, I., W. Szyrmer, C. Bell, and F. Fabry, 2005: Modeling of the melting layer. Part III: The density effect. J. Atmos. Sci., 62, 3705-3723. 